\title{
Fighting COPD Together-The COPD National Action Plan
}

\author{
An expert interview with Antonello Punturieri
}

Division of Lung Diseases, National Heart, Lung and Blood Institute, National Institutes of Health, Bethesda, MD, US

DOI: https://doi.org/10.17925/USRPD.2017.12.02.15

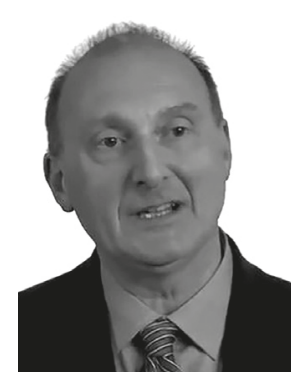

\begin{abstract}
Antonello Punturieri
Antonello (Tony) Punturieri, MD, PhD, is a Program Officer in the Division of Lung Diseases (DLD), National Heart, Lung and Blood Institute (NHLBI), National Institutes of Health (NIH). In this capacity Tony administers a varied portfolio of grants, and contracts in the area of chronic obstructive pulmonary disease (COPD) and environment. Specifically, Tony participates in the development and administration of programs that aim at furthering the understanding of COPD disease mechanisms, COPD prevention, and the testing and evaluation of COPD therapies.
\end{abstract}

Tony attended medical school in Ferrara (Italy) and obtained a PhD in Immunology at "La Sapienza" University in Rome, Italy. He spent four years at the NIH as a Visiting Fellow at the National Institute of Diabetes and Digestive and Kidney Diseases (NIDDK) and Visiting Associate at the National Institute of Allergy and Infectious Diseases (NIAID). He returned to Rome as Assistant Professor of Pathophysiology at "La Sapienza" University in Rome (Italy) while also working as Staff Scientist at "Regina Elena" Cancer Institute. He then moved to the Division of Hematology/Oncology at the University of Michigan, Ann Arbor and subsequently joined the Pulmonary Division at Michigan and the Veterans Administration Hospital (Pulmonary Section) in Ann Arbor. He joined NHLBI in 2006.

\section{Keywords}

Chronic obstructive pulmonary disease, COPD, national action plan

Disclosure: Antonello Punturieri is an employee of the National Institutes of Health and has no other disclosures in relation to this article. This is an expert interview and, as such, has not undergone the journal's standard peer review process.

Authorship: All named authors meet the International Committee of Medical Journal Editors (ICMJE) criteria for authorship of this manuscript, take responsibility for the integrity of the work as a whole, and have given final approval to the version to be published.

open Access: This article is published under the Creative Commons Attribution Noncommercial License, which permits any noncommercial use, distribution, adaptation, and reproduction provided the original author(s) and source are given appropriate credit.

Received: November 22, 2017

Published Online: December 12, 2017

Citation: US Respiratory \& Pulmonary Diseases, 2017;2(1):15-6

Corresponding Author: Antonello Punturieri, Division of Lung Diseases, National Heart, Lung, and Blood Institute, 6701 Rockledge Drive, Bethesda, MD 20892-7952, US. E: punturieria@nhlbi.nih.gov

Support: No funding was received in the publication of this article. $\mathrm{n}$ an expert interview, Antonello Punturieri, Program Officer at the DLD, NHLBI, NIH, discusses the COPD National Action Plan. This was the topic of his presentation which took place during a multiperspective panel discussion session at the recent 11th General Meeting of the Global Alliance Against Chronic Respiratory Diseases (GARD, supported by the World Health Organization) held in Brussels, Belgium (www.who.int/gard/en/). From healthcare providers and federal partners to advocacy groups and patients, everybody in the COPD community can and must play a role in supporting and moving this important initiative forward.

\section{Q: Why was there a need for a COPD National Action Plan?}

Chronic obstructive pulmonary disease (COPD) is the third leading cause of death in the US and is the fourth leading cause of disability. Some 15\% of people with a disability have COPD. In 2010, more than $\$ 32$ billion was spent on COPD-related patient care; and those costs are projected to increase to $\$ 49$ billion by 2020 . While death from chronic conditions like heart disease, cancer, stroke, and diabetes continue to decline, COPD is the only one of the six leading causes of death that has not seen a similar decline. The nation is finally recognizing COPD as a serious disease that requires intervention from all involved. ${ }^{1-5}$

In the 2012 Senate Appropriations Committee report, Congress highlighted the importance of COPD and encouraged the NIH "to work with community stakeholders and other federal agencies, including the CDC [Centers for Disease Control and Prevention], to develop a national action plan to respond to the growing burden of this disease." A letter to the NIH and CDC from Reps. John Lewis (D-GA), David Joyce (R-OH) and Carol Shea-Porter (D-NH) on November 2014 requested "that the two agencies create a National Action Plan for COPD in fiscal year 2015." In response to these requests and in collaboration with the CDC and other federal partners, the NHLBI-the NIH component with primary responsibility for chronic lung disease_organized a series of events and activities. 


\section{Q: What are the main goals of the initiative?}

The COPD National Action Plan is divided into five goals covering five inter-related areas, each designed to address a different aspect of the disease. The five goals are:

1. Empower people with COPD, their families, and caregivers to recognize and reduce the burden of COPD.

2. Improve the prevention, diagnosis, treatment, and management of COPD by improving the quality of care delivered across the health care continuum.

3. Collect, analyze, report, and disseminate COPD-related public health data that drive change and track progress.

4. Increase and sustain research to better understand the prevention, pathogenesis, diagnosis, treatment, and management of COPD.

5. Translate national policy, educational, and program recommendations into research and public health care actions.

The entire community, including federal and nonfederal partners, made the plan possible, and the continued involvement of all is critical to its implementation. Each organization is encouraged to implement and adapt the Action Plan elements that are most relevant to its organization's area of specialty and most feasible for its capacity.

\section{Q: How was the plan developed?}

Following a request from Congress, the NHLBI organized two transgovernmental workshops and held additional conference calls in 2013 and 2014 to discuss the structural and scientific environment for the Action Plan and to establish initial goals the Action Plan was to address.

In early 2016, the NHLBI convened the COPD community for a COPD Town Hall on the NIH Campus in Bethesda, MD. Federal and nonfederal partners, including patients and their families, health care providers, academia, and industry, came together for the two-day meeting and discussed each goal. The discussions directly informed the Action Plan, and the community remained closely involved as the Action Plan was further developed and refined. In October 2016, the NHLBI invited the public to review and comment on the draft Action Plan. It carefully considered all feedback before finalizing the COPD National Action Plan and soliciting reviews from other federal agencies.

\section{Q: How will the plan be implemented?}

The implementation discussions and activities for the COPD National Action Plan are in the planning phase and many already begun in the months following the public launch of the plan at the American Thoracic Society (ATS) international meeting held in Washington DC this past May. A formal meeting of COPD stakeholders will be held during 2018 to discuss and establish implementation goals and strategies. Some of these initial activities may involve the development of benchmarks to evaluate outcomes of each goal. Surely a measure of success for the Action Plan will be its use and adoption by partner organizations and states nationwide.

Anyone interested in being part of the national effort to address COPD, should visit COPD.nih.gov. In addition, a list of organizations already expressing interest and enthusiasm in activities aligned with the goals of the COPD National Action Plan can be found in the plan. If you are served by these organizations in any way, you should feel free to reach out to them directly.

\section{Q: What resources are available to healthcare providers to help them implement the plan?}

Currently, no federal funding is specifically appropriated for the execution of the COPD National Action Plan. Many agencies and organizations are already engaged in activities that support some components of the Action Plan. However, with additional resources, more could be done and perhaps done faster. In addition, more organizations could be engaged if resources were available.

A variety of tools are available to promote the COPD National Action Plan including a digital toolkit, fact sheet, video, animations, and social media resources. These can all be found at COPD.nih.gov. $\square$
1. Kochanek KD, Murphy SL, XU JQ, Tejada-Vera B. Deaths: Final data for 2014. National Vital Statistics Reports, 2016;65, Hyattsville, MD: National Center for Health Statistics. 2016, Available at: www. cdc. gov/nchs/data/nvsr/nvsr65/nvsr65 04.pdf (accessed December $5,2017)$.

2. Wheaton AG, Cunningham TJ, Ford ES, Croft JB, Employment and activity limitations among adults with chronic obstructive pulmonary disease - United States, 2013, MMWR Morb Mortal Wkly Rep, 2015; 64: 289-95, Available at: www.cdc.gov/mmwr/ $\mathrm{pdf} / \mathrm{wk} / \mathrm{mm} 6411 . \mathrm{pdf}$ (accessed December 5, 2017).

3. Ma J, Ward EM, Siegel RL, Jemal A. Temporal trends in mortality in the United States, 1969-2013, JAMA, 2015;314:1731-9.

4. Brault MW, Hootman J, Helmick CG, et al., Prevalence and most common causes of disability among adults - United States,
2005, MMWR Morb Mortal Wkly Rep, 2009;58:421-26, Available at: www.cdc.gov/mmwr/preview/mmwrhtml/mm5816a2.htm (accessed December 5, 2017).

5. Ford ES, Murphy LB, Khavjou O, et al., Total and state-specific medical and absenteeism costs of COPD among adults aged $\geq 18$ years in the United States for 2010 and projections through 2020, Chest, 2015;147:31-45. 